\title{
Studies of the Human Liver Insulin Receptor in Noninsulin-dependent Diabetes Mellitus
}

Peter Arner, Kurt Einarsson, Staffan Ewerth, and James Livingston* Departments of Medicine and Surgery, Huddinge Hospital, Karolinska Institute, S-141 86 Huddinge, Sweden; *Department of Medicine, University of Rochester School of Medicine and Dentistry, Rochester, New York 14642

\begin{abstract}
The insulin binding characteristics and the structural components of the insulin receptor were studied in the purified liver plasma membranes from seven patients with noninsulin-dependent diabetes (NIDDM) and seven control subjects. In comparison to the controls, diabetic subjects had a $65 \%$ reduction in plasma insulin levels in response to an oral glucose load. Specific insulin binding by liver membranes from diabetic patients was, however, twofold greater than the binding activity by membranes from control subjects. This alteration resulted largely from an increase in the number of insulin receptors and a modest increase in receptor binding affinity. Holo (nonreduced) receptor species of similar molecular weights were detected by an affinity labeling technique in the two membrane preparations and sulfhydryl reduction demonstrated an insulin binding subunit of $125,000 \mathrm{~mol}$ wt. Overall, these results show that the hepatic insulin resistance of NIDDM cannot be explained by a deficiency in insulin binding.
\end{abstract}

\section{Introduction}

Hepatic resistance to insulin action is a common feature of noninsulin dependent diabetes mellitus (NIDDM) ${ }^{1}$ in human subjects (1). The underlying cause of this resistance is not known but presumably it involves one or more steps that lead to an insulin response. The insulin receptor occupies a central position in this process, since it initiates the subsequent cellular responses by binding insulin (2). In previous studies of human obesity, another condition of insulin resistance (3), a marked decrease in the number of insulin receptors was demonstrated in the hepatic liver membranes (4). We have examined the insulin binding properties and structural characteristics of the liver insulin receptor in NIDDM.

\section{Methods}

Human subjects. Seven diabetics and seven control subjects were studied. They were admitted to the Huddinge Hospital for elective cholecystec-

Please address reprint requests to Dr. Livingston. Received for publication 13 December 1985.

1. Abbreviations used in this paper: NIDDM, noninsulin-dependent diabetes mellitus.

J. Clin. Invest.

(C) The American Society for Clinical Investigation, Inc.

0021-9738/86/05/1716/03 \$1.00

Volume 77, May 1986, 1716-1718 tomy; they were otherwise healthy and free of additional diseases. Three individuals in each group were overweight; the remaining subjects were nonobese. All diabetics had NIDDM, ranging in duration from 5 to 10 yr. Four subjects were treated by diet and a sulfonylurea drug (Glyburide, Hoechst-Roussel Pharmaceuticals, Frankfurt, FRG); the remaining patients were treated by diet alone. All diabetic and control subjects were admitted to the hospital seven days prior to surgery and maintained on the same normal iso-caloric diet of $45 \%$ carbohydrate, $20 \%$ protein, and $35 \%$ fat. During this period, sulfonylurea therapy was stopped in those diabetics that received the drug. It was not necessary to give these subjects additional antidiabetic therapy during the study.

On the morning of day seven after an overnight fast, venous blood samples were obtained for the measurement of plasma glucose and insulin as described (4). A 100-g oral glucose load was given and plasma glucose and insulin levels were followed for $2 \mathrm{~h}$. On the morning of day eight after an overnight fast, general anesthesia was induced with a shortacting barbiturate and maintained with phentanyl and nitrous oxide. After the laparotomy and before the cholecystectomy, a 1-g liver biopsy was taken from the left lobe of the liver. Histologic evaluation was carried out in these biopsies in addition to the insulin receptor studies. Except for slight fatty infiltration in the livers of one diabetic and one control subject, no other abnormalities were noted.

This study was approved by the Ethical Committee of the Karolinska Institute. Informed consent was obtained from each subject after he or she was given a detailed description of the study.

Studies of the insulin receptor. The liver plasma membrane fraction was isolated from the biopsy material using an aqueous two-phase polymer method exactly as previously described (4). (In studies of 19 human subjects the coefficient of variance for the recovery of plasma membranes by this procedure was $10 \%$ [4].) The membranes were kept at $-80^{\circ} \mathrm{C}$ and transported to the University of Rochester for studies of the insulin receptor. The studies of insulin binding were carried out with the reagents and incubation conditions previously described (4). In brief, plasma membranes (approximately $21 \mu \mathrm{g}$ protein) were incubated with ${ }^{125} \mathrm{I}$-insulin ( $75 \mathrm{pM})$ in the presence or absence of the indicate concentrations of native insulin for $2 \mathrm{~h}$ at $21^{\circ} \mathrm{C}$. The incubation was terminated and the amount of specifically bound hormone was determined as described (4). Under these conditions the degradation of ${ }^{125}$ I-insulin was $<10 \%$ of the total in the binding assay.

The structure of the insulin receptor was examined by affinity labeling techniques and sodium dodecyl sulfate electrophoresis as described (4) before and after treatment with $100 \mathrm{mM}$ 2-mercapthoethanol. The autoradiograms were scanned with a laser densitometer.

Statistical analysis. The values presented are mean \pm SE. Statistical differences were determined by the Student's unpaired $t$ test.

\section{Results}

The clinical characteristics of the two study groups are given in Table I. There were no differences in the groups with regard to sex, age, and body weight. The diabetic individuals had significant fasting hyperglycemia but their fasting insulin levels did not differ from those of the control subjects. The results from the oral 
Table I. Characteristics of Seven Noninsulin-dependent Diabetics and Seven Control Subjects

\begin{tabular}{|c|c|c|c|c|c|c|c|c|c|c|c|}
\hline \multirow{2}{*}{$\begin{array}{l}\text { Study } \\
\text { group }\end{array}$} & \multirow{2}{*}{$\begin{array}{l}\text { Sex } \\
(M / F)\end{array}$} & \multirow[b]{2}{*}{ Age } & \multirow{2}{*}{$\begin{array}{l}\text { Body-weight } \\
\text { percent average }\end{array}$} & \multicolumn{4}{|c|}{ Plasma glucose } & \multicolumn{4}{|c|}{ Plasma insulin } \\
\hline & & & & $0 \mathrm{~min}$ & $30 \min$ & $60 \mathrm{~min}$ & $120 \mathrm{~min}$ & $0 \min$ & $30 \mathrm{~min}$ & $60 \mathrm{~min}$ & $120 \mathrm{~min}$ \\
\hline & & $y r$ & & mmol/liter & mmol/liter & $\mathrm{mmol} / \mathrm{liter}$ & mmol/liter & mU/liter & mU/liter & mU/liter & mU/liter \\
\hline Diabetics & $4 / 3$ & $61 \pm 3$ & $112 \pm 7$ & $8.0 \pm 0.7$ & $11.0 \pm 1.0$ & $12.5 \pm 1.2$ & $14.6 \pm 1.8$ & $7.7 \pm 2.5$ & $20.8 \pm 4.8$ & $27.9 \pm 7.8$ & $46.2 \pm 10.5$ \\
\hline Controls & $3 / 4$ & $53 \pm 5$ & $111 \pm 7$ & $4.6 \pm 0.2$ & $8.0 \pm 0.4$ & $7.5 \pm 0.6$ & $6.9 \pm 0.4$ & $7.5 \pm 2.0$ & $53.4 \pm 9.5$ & $73.0 \pm 12.5$ & $99.6 \pm 18.3$ \\
\hline$P$ & NS & NS & NS & $<0.001$ & $<0.02$ & $<0.005$ & $<0.005$ & NS & $<0.02$ & $<0.02$ & $<0.02$ \\
\hline
\end{tabular}

Values are mean \pm SE. The average body weight was obtained from tables adjusted for height, age, and sex from Documenta Geigy, Ciba-Geigy, Ltd., Basel, Switzerland. Statistical difference was tested using Student's unpaired two-tailed $t$ test, NS, not significant.

glucose tolerance test were normal for each control subject but abnormal for each diabetic. The glucose values at 30 and 60 min were $\sim 2.5$ times higher in the control patients. A slight but not statistically significant increase in the fasting blood glucose level for the diabetic group was observed at day 7 when it was compared to the level for day 1.

The ability of the liver plasma membranes from each group to specifically bind insulin is shown in Fig. 1. Competition curves show a marked increase in insulin binding by membranes from diabetic subjects over the range of insulin concentrations tested (Fig. $1 A)$. With physiologic insulin concentrations $(0.5-5 \mathrm{ng} /$ $\mathrm{ml}$ ), a twofold increase in insulin binding over control values was present in membranes from NIDDM subjects. Scatchard transformation of the binding data (5) yielded two nonlinear plots that were almost parallel with a rightward shift in the curve for the diabetics (Fig. $1 B$ ). This indicates an increase in the total insulin binding capacity of the plasma membranes from the diabetic subjects. Total insulin receptor number was not determined, however, since this extrapolation from the nonlinear curves is highly inaccurate (6).

The binding affinity of the insulin receptor was examined by determining the concentration of native insulin that reduces ${ }^{125} \mathrm{I}$-insulin binding by $50 \%$ (4). This value was $29 \pm 7 \mathrm{ng} / \mathrm{ml}$ insulin for the control group and $16 \pm 2 \mathrm{ng} / \mathrm{ml}$ for the diabetics $(P$ $<0.05$ ). A moderate increase in the insulin binding affinity of the receptor thus was observed in NIDDM.

The molecular weight properties of the liver insulin receptor were studied by affinity labeling techniques and sodium dodecyl sulfate electrophoresis (Fig. 1 C). Both groups demonstrated a major holo (nonreduced) insulin binding species of $300,000 \mathrm{~mol}$ wt and minor species of 350,000 and 260,000-280,000 mol wt (i.e., the right shoulder of the 300,000 -mol wt peak). No consistent differences in the proportion of these species could be detected after the analysis of data from four separate membrane preparations from four individuals in each group. Further studies showed that the insulin binding subunit of the receptors in both groups has a value of $125,000 \mathrm{~mol}$ wt (data not shown).

\section{Discussion}

The present results show that insulin binding to hepatic plasma membranes is elevated in NIDDM. At physiologic hormone concentrations, insulin binding was increased approximately twofold in the diabetics. It is not likely that this difference in binding was produced by methodological variations or clinical differences between the two groups. Insulin binding was simul- taneously determined in all of the membrane preparations, and the intervariation in the recovery of plasma membranes from the biopsies by the method used is low (4). Both study groups were investigated as in-patients one week before surgery. During this period, all patients received the same diet, and sulfonylurea therapy was discontinued. Furthermore, the two groups were carefully matched for age, sex, and body weight; factors that could influence insulin binding activity.

Analysis of the binding data indicated that an increase in total number of insulin receptors was largely responsible for the elevated insulin binding activity in the diabetic subjects. An increase in the insulin binding affinity of the receptor was also observed, however, which helps contribute to the change. These changes occurred in the absence of any structural alterations in the receptor, at least as measured by the affinity labeling technique and sodium dodecyl sulfate electrophoresis. Although this method provides a reasonable estimate of molecular weight, small changes in structure may not be detected. It is possible, therefore, that changes may exist in other properties of the receptor, such as in its tyrosine kinase activity (2).

These results with insulin binding are opposite from our previous findings in human obesity (4), in which the insulin binding activity by liver membranes was decreased below the control value. Therefore, the human liver insulin receptor is apparently "up-regulated" in NIDDM and "down-regulated" in obesity even though hepatic insulin resistance exists in both conditions $(1,3)$. The mechanism(s) that underlies these opposite phenomena are unknown but the level of circulating insulin may play an important role. As recently reviewed $(1,3)$, several studies have suggested that the prevailing concentration of insulin may modulate insulin binding, with an overall inverse relationship between insulin receptor number and plasma insulin level. The diabetic subjects in the present study had normal fasting insulin levels and blunted insulin responses to oral glucose, indicative of a relative insulin-deficient state.

In contrast, the obese subjects in our previous study had fasting hyperinsulinemia and an enhanced insulin response to oral glucose (4). If circulating insulin plays a regulatory role, the impaired insulin secretion in NIDDM may be an important causative factor in the increase in insulin binding. Further support for this possibility is available from studies of streptozotocin diabetic rats, an animal model with similarities to NIDDM. Several laboratories have shown that insulin binding is increased in the liver membranes from these animals $(7,8)$.

Although the findings with liver demonstrate changes in insulin binding in NIDDM and obesity, parallel alterations in other 

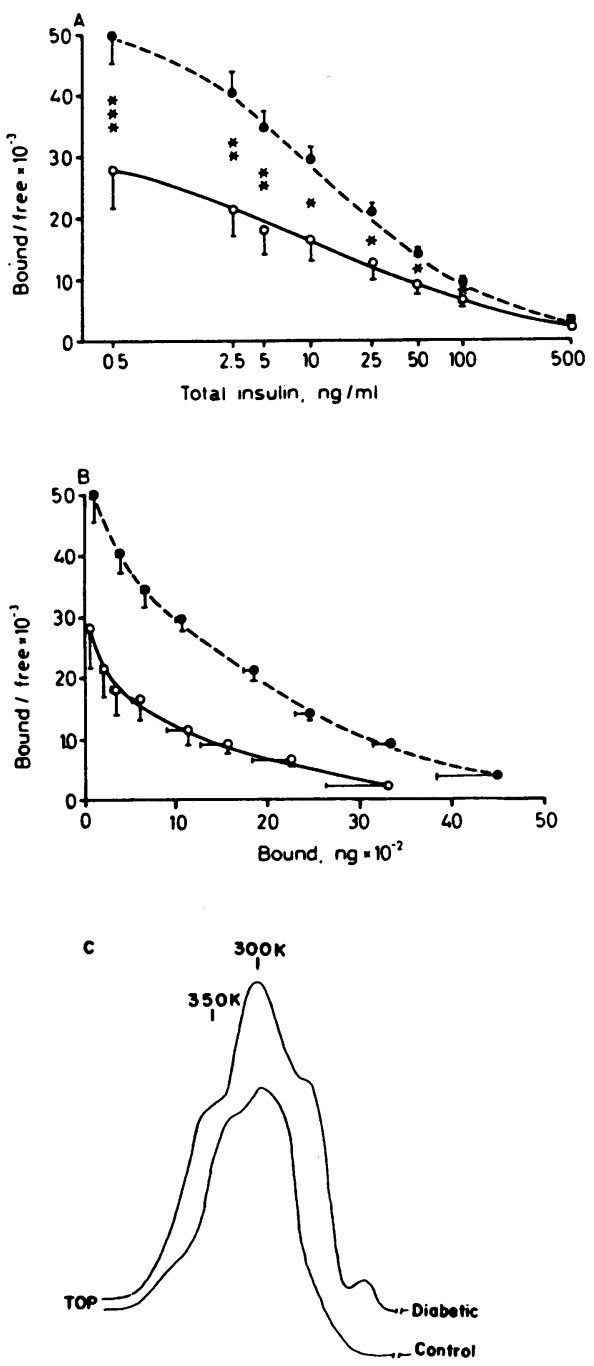

Figure 1. Studies of insulin binding and receptor structure. In these studies insulin binding was measured in liver plasma membranes from control (0) and diabetic ( $\bullet$ ) subjects as described in Methods. The results are expressed per $21 \mu \mathrm{g}$ of membrane protein. Nonspecific insulin binding in these studies ranged from 10 to $15 \%$ of the total binding measured with $75 \mathrm{pM}$ of ${ }^{125}$ I-insulin. $(A)$ Specific insulin binding plotted as a competition curve. ${ }^{* * *}, P<0.001 ; * *, P<0.01 ; *, P<0.05$. $(B)$ Insulin binding data expressed as Scatchard plots. $(C)$ Laser densitometer scans of the autoradiogram of the affinity-labeled insulin receptors from a control and a diabetic subject. In this study, the radiolabeled insulin receptors were subjected to sodium dodecyl sulfate electrophoresis in the absence of disulfide reduction as described in Methods. Nonspecific labeling was insignificant in these studies (not shown). No other material was labeled in these gels other than the peaks shown. Note that the scans have been broken, i.e., only portions of the lanes with radioactivity are illustrated. $350 \mathrm{~K}$ and $300 \mathrm{~K}$ indicate the molecular weight of the labeled material as determined by high molecular weight cross-linked standards (BDH Chemicals, Poole, England; 336,000 to $56,000 \mathrm{~mol} \mathrm{wt}$ ). The height of each peak is in relative units with the scale set at the same sensitivity for both scans. insulin target tissues from affected subjects may not occur. For example, adipocytes from patients with NIDDM, who were similar to those studied in the present report, failed to show an alteration in either the number of insulin receptors or their binding affinity (9). The relative stability of the adipocyte insulin receptor was also noted in obesity. We have found that insulin binding in this disorder remains normal, at least when the binding activity is expressed on the basis of cell number (10). These differences between fat and liver argue for disparate effects of metabolic and endocrine disorders on the insulin receptor system of different tissues and emphasize the problems of using receptor measurements from one tissue to deduce the status of the receptor in another.

In summary, the present study shows that the insulin resistance in NIDDM is not caused by a decrease in insulin binding by the insulin receptor. These results indicate that the alteration responsible for the hepatic insulin resistance in this condition exists at a site beyond the initial interaction between the hormone and the liver cell.

\section{Acknowledgments}

This work was supported by grants from the Swedish Medical Research Council, the Swedish Medical Association, the Trone Holst Foundation, the Swedish Diabetes Association, The Karolinska Institute, the Foundations of Folksam and Nordic Insulin, and National Institutes of Health grant AM 25116.

\section{References}

1. DeFronzo, R. A., E. Ferrannini, and V. Koivisto. 1983. New concepts in the pathogenesis and treatment of non-insulin-dependent diabetes mellitus. Ann. J. Med. 74(Suppl. 1):52-81.

2. Czech, M. P. 1985. The nature and regulation of the insulin receptor: structure and function. Annu. Rev. Physiol. 47:357-381.

3. Olefsky, J. M., and O. G. Kolterman. 1981. Mechanisms of insulin resistance in obesity and non-insulin dependent (Type II) diabetes. Annu. J. Med. 70:151-168.

4. Arner, P., K. Einarsson, L. Backman, K. Nilsell, K. M. Lerea, and J. N. Livingston. 1983. Studies of liver insulin receptors in non-obese and obese human subjects. J. Clin. Invest. 72:1729-1736.

5. Scatchard, G. 1949. The attraction of proteins for small molecules and ions. Ann. NY Acad. Sci. 51:660-672.

6. Klotz, I. M. 1982. Numbers of receptors sites from Scatchard graphs: facts and fantasies. Science (Wash. DC). 217:1247-1248.

7. Davidson, M. D., and S. A. Kaplan. 1977. Increased insulin binding by hepatic plasma membranes from diabetic rats. J. Clin. Invest. 59:2230.

8. Cech, J. M., R. B. Freeman, Jr., J. F. Caro, and J. N. Amatruda. 1980. Insulin action and binding in isolated hepatocytes from fasted, streptozotocin-diabetic, and older, spontaneously obese rats. Biochem. J. 188:839-845.

9. Bolinder, J., J. Östman, and P. Arner. 1982. Postreceptor defects causing insulin resistance in normoinsulinemic non-insulin-dependent diabetes mellitus. Diabetes. 31:911-916.

10. Livingston, J. N., K. M. Lerea, J. Bolinder, L. Kager, L. Backman, and P. Arner. 1984. Binding and molecular weight properties of the insulin receptor from omental and subcutaneous adipocytes in human obesity. Diabetologia. 27:447-453. 